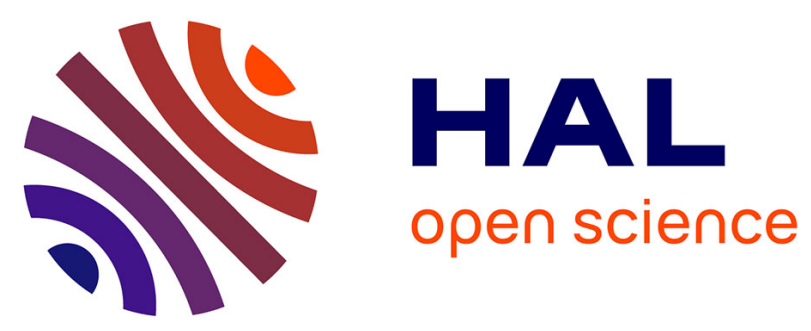

\title{
Daily variations of ELF data observed by a low-altitude satellite
}

Michel Parrot, O. A Molchanov, M. M Mogilevski, François Lefeuvre

\section{To cite this version:}

Michel Parrot, O. A Molchanov, M. M Mogilevski, François Lefeuvre. Daily variations of ELF data observed by a low-altitude satellite. Geophysical Research Letters, 1991, 18 (6), pp.1039-1042. 10.1029/91GL01352 . insu-03039738

\section{HAL Id: insu-03039738 \\ https://hal-insu.archives-ouvertes.fr/insu-03039738}

Submitted on 4 Dec 2020

HAL is a multi-disciplinary open access archive for the deposit and dissemination of scientific research documents, whether they are published or not. The documents may come from teaching and research institutions in France or abroad, or from public or private research centers.
L'archive ouverte pluridisciplinaire $\mathbf{H A L}$, est destinée au dépôt et à la diffusion de documents scientifiques de niveau recherche, publiés ou non, émanant des établissements d'enseignement et de recherche français ou étrangers, des laboratoires publics ou privés. 


\title{
DAILY VARIATIONS OF ELF DATA OBSERVED BY A LOW- ALTITUDE SATELLITE
}

\author{
M. PARROT ${ }^{1}$, O.A. MOLCHANOV ${ }^{2}$, M.M MOGILEVSKI ${ }^{3}$ AND F. LEFEUVRE ${ }^{1}$
}

\begin{abstract}
Data from a low-orbiting satellite with a quasipolar orbit have been studied to determine if man-made waves, such as the Power Line Harmonic Radiations (PLHR), can affect the intensity of the ELF waves observed in the ionosphere. The signals coming from two electric components were processed with a system of 6 filters (from $10 \mathrm{~Hz}$ up to $1000 \mathrm{~Hz}$ ), and recorded on-board all around the Earth. Most ELF waves derive from electrostatic turbulence. It is shown that the signal recorded by the electric component that is parallel to the Earth's magnetic field has a modulation depending of the days of the week. The amplitude is maximum on Monday and decreases until Saturday. The largest difference between Monday and Saturday (93\%) occurs with the filter centered around $72 \mathrm{~Hz}$. The interpretation of the experimental results supposes that the intensity of the ELF waves is connected to the PLHR influence on the ionospheric plasma. A theory is presented to explain this variation: the PLHR emitted from the ground during weekdays are different from those of the weekend, not only because power consumption is lower, but also because the ground configuration of their sources is changed.
\end{abstract}

\section{Introduction}

For many years attempts have been made to demonstrate that the Power Line Harmonic Radiations (PLHR) influence the atmosphere-ionosphere-magnetosphere coupling. The PLHR are the ELF and VLF waves radiated by the electric power systems at the harmonic frequencies of 50 or $60 \mathrm{~Hz}$. These electromagnetic waves are supposed to amplify and to trigger many emissions, and thus to participate in the precipitation of electrons from the slot region. This phenomenon could be important as the electricity consumption increases quickly in the world: $1200 \mathrm{TWh}$ in $1955,9600 \mathrm{TWh}$ in 1985 .

The propagation of the PLHR through the magnetosphere was first observed by Helliwell et al. [1975], but only on the ground at a conjugate point of an industrialized region. Similar observations on the ground were made from different places by Matthews and Yearby [1981] and Kimura et al. [1987]. Rare and weak PLHR emissions were observed onboard the satellites ISEE-1 [Bell et al., 1982] above North America and AUREOL-3 [Berthelier et al., 1982] above Western Europe. However, studies with the low-altitude

\footnotetext{
${ }^{1}$ Laboratoire de Physique et Chimie de 1'Environnement, CNRS, Orléans, France

${ }^{2}$ Institute of Physics of the Earth, Moscow 123810, USSR

${ }^{3}$ Space Research Institute, Moscow 117810, USSR

Copyright 1991 by the American Geophysical Union.

Paper number 91GL01352

$0094-8534 / 91 / 91 \mathrm{GL}-01352 \$ 3.00$
}

satellites ARIEL 3 and 4 have revealed a permanent zone of enhanced VLF activity over North America, attributed mainly to the PLHR and partly to the lightning activity [Bullough et al., 1976]. Increases of the magnetic field strength at the fundamental frequencies 50 and/or $60 \mathrm{~Hz}$ in the topside ionosphere have been reported by Tomizawa and Yoshino [1985].

This paper studies the variation of the electric field at low frequencies $(<1000 \mathrm{~Hz}$ ) observed by the low-altitude and polar-orbiting satellite AUREOL-3. This low-frequency electric noise is more intense in the high-latitude ionosphere and known as electrostatic turbulence. One of the first observations of such an electrostatic turbulence at low altitudes was made by Kelley and Mozer [1972] on OV1-17. High-altitude measurements of electric fields at high latitudes were made earlier by polar-orbiting satellites such as S3-3 [Temerin, 1978] and VIKING [Lindquist and Marklund, 1990]. In the same frequency range, both electric and magnetic fluctuations [Kintner, 1976; Gurnett et al., 1984] have been observed over the auroral zones. On AUREOL-3, this type of noise was studied by Berthelier et al. [1988] and Mounir [1989] using the high-resolution data. Kintner and Seyler [1985] and Mounir [1989] have reviewed and discussed the high-latitude turbulence phenomena and the associated plasma instabilities. Two different models are generally invoked to interpret the observations: a static model and an Alfven-wave model. [Gumett et al, 1984; Berthelier et al., 1988]. In the static model, the electric and magnetic field noise is attributed to the motion of the satellite through fieldaligned current systems in the ionosphere, whereas in the Alfven-wave model the noise is thought to be due to electromagnetic waves propagating along the auroral field lines at frequencies below the ion cyclotron frequency.

\section{Data}

The wave experiment $A R C A D-3$ was placed into a quasipolar orbit on board the triaxial-stabilized satellite Aureol-3 (apogee $2012 \mathrm{~km}$, perigee $408 \mathrm{~km}$, inclination 82 ${ }^{\circ}$, , period 109.5 min), launched on 21 September 1981. ARCAD-3 measured three magnetic and two electric components of the waves in the ELF and VLF range, from $10 \mathrm{~Hz}$ up to $15 \mathrm{kHz}$. For this paper, statistical studies only concerned the onboard recorded data, to allow a complete coverage of the Earth in geographical coordinates. The two electric components $\mathrm{E}_{H}$ and $E_{Z}$ were processed in a bank of six filters named $F B E$ (center frequencies: $15,32,72,150,325$ and $725 \mathrm{~Hz}$ ) on a routine basis. Depending on the programming of the experiment, two sensors were selected from the three magnetic and the two electric antennae and connected to the FBF (wide-band filters with center frequencies: 250,700 , $1250,2200,3900,7000$ and $12500 \mathrm{~Hz}$ ) and FBS (narrowband filters with center frequencies: $140,450,800,4500$ and $15000 \mathrm{~Hz}$ ) filterbanks [Berthelier et al., 1982]. The $\mathrm{E}_{Z}$ 
component was approximately parallel to the Earth's magnetic field at high latitude, the $E_{H}$ component being nearly perpendicular. Two sampling frequencies of the filters were used: ZAP3 (400 points every $128 \mathrm{~s}$ ) and ZAP4 (50 points every $128 \mathrm{~s}$ ). Data from October 1981 until December 1983 were taken into account and a data set with average values $(\sim 22000)$ was obtained for each filter [Parrot, 1990].

Figure 1 shows the average amplitude of the signal recorded by the electric component $\mathrm{E}_{\mathbf{Z}}$ in the filter centered around $72 \mathrm{~Hz}$. This amplitude is represented as a function of the days of the week and the error bars indicate the standard deviations. The days of the week are defined in local time at the sub-satellite longitude. The maximum value $0.11 \mathrm{mV} \cdot \mathrm{m}^{-1} . \mathrm{Hz}^{-1 / 2}$ occurs on Monday, after which the signal decreases until Saturday. A rise is observed on Sunday. This behaviour is the same for all the six filters, but the difference between the average amplitudes on Monday and Saturday decreases from a maximum of $93 \%$ for the $72 \mathrm{~Hz}$ filter to only $48 \%$ for the $725 \mathrm{~Hz}$ filter. Average power laws in frequency have been estimated to check the turbulent character of the electric signal, and Figure 2 shows the average amplitudes recorded by $\mathrm{E}_{\mathcal{Z}}$ in the six FBE filters. The curves corresponding to Monday and Saturday are plotted in solid lines as a function of the frequency and the error bars indicate the standard deviations. The dotted line represents a power spectrum in frequency space with a power-law index of $-5 / 3$. It can be seen that the data on Monday and Saturday have the same dependency except for the filter at the highest frequency. Therefore, the data recorded during the different days of the week are assumed to be of the same nature and are consistent with interpretation as electrostatic turbulence. Their properties are similar to high-latitude turbulence shown by Kelley and Mozer [1972], and Kintner [1976] at low altitudes in the ionosphere. The behaviour of the waves in the last filter around $725 \mathrm{~Hz}$ is different because this filter integrates hiss events regularly observed above the local proton gyrofrequency (the maximum proton gyrofrequency seen on AUREOL-3 is about $600 \mathrm{~Hz}$ ). The data processing shown in Figure 1 was also performed with the component $\mathrm{E}_{\mathrm{H}}$, but it does not show the same variation.

The validity of the data can be checked in two different

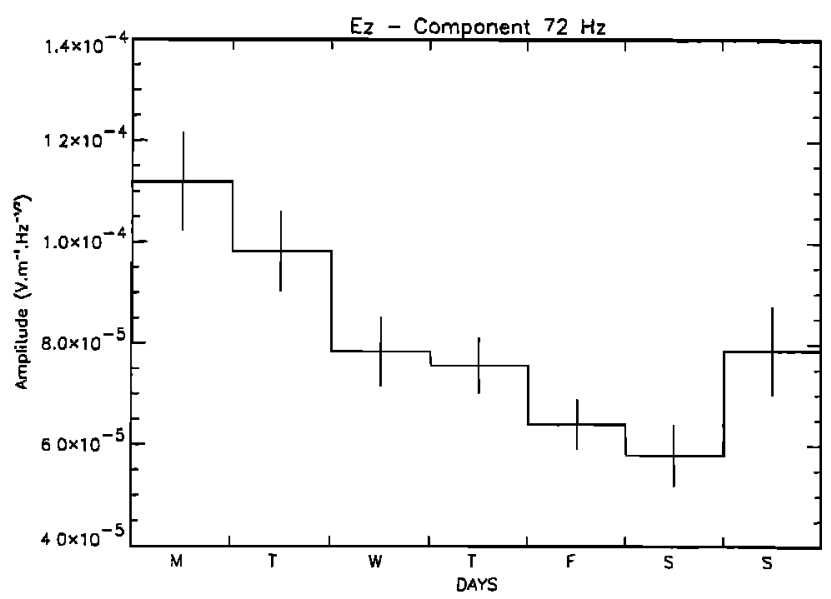

Fig. 1. Average electric-field value recorded by the component $E_{Z}$ in a narrow band filter around $72 \mathrm{~Hz}$, as a function of the days of the week. The vertical lines are error bars.

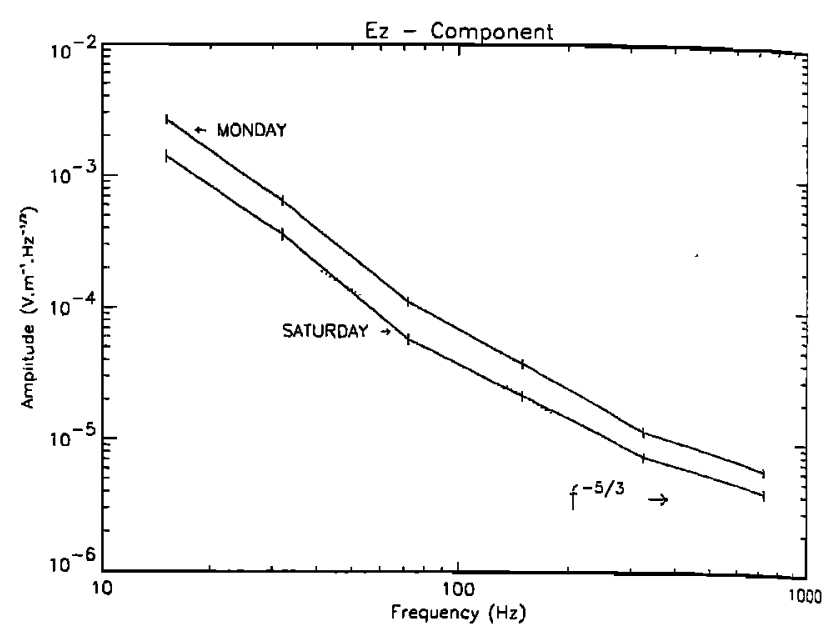

Fig. 2. Average electric-field value recorded by the component $\mathrm{E}_{\mathbf{Z}}$ and taken during two days of the week: Monday and Saturday. The data are represented as a function of the frequency, and the error bars are indicated. The dotted line represents a variation in frequency proportional to $\mathrm{f}^{5 / 3}$.

ways: not only, do the FBE, FBS and FBF filters have overlapping frequency ranges, but the data sets can also be randomly separated in two parts as is usual in statistical studies. The choice was made to consider both the whole data set (ZAP3 + ZAP4) and a data set with ZAP3 only, because the average values contained in ZAP4 might be questionable. These average values are certainly affected by the fact that if, in the cyclic mode of operation, the two components connected to the filters FBS and FBF are changed too quickly with respect to the integration time of the filters, then spurious peaks can appear in the telemetry just after a sudden change. This phenomenon is negligible for ZAP3 as the number of points in an average value is 8 times larger. There is also a fixed mode of operation which gave no problems. Figure 3 represents the ratio between the average value on Mondays and the average value for all the days as a function of the frequency. In the upper panel it concerns the component $E_{Z}$ and in the lower the component $E_{H}$. The solid and the dashed lines represent, respectively, the ratio for the ZAP3 data set and the ratio for the whole data set (ZAP3 + ZAP4). A line joins the FBS and FBF filters points. In each case the error bars are indicated. Before discussing the main characteristics of Figure 3 four points must be underlined: a) the FBE, FBS and FBF filters do not have the same properties which is why a ratio is plotted instead of an absolute value; b) the FBS and FBF filters were working simultaneously with the same two components; c) the components $E_{H}$ and $E_{Z}$ are not connected to the FBS and FBF filters during the same time; d) in contrast, $E_{H}$ and $E_{Z}$ are always connected to the FBE filters, which means that their corresponding data sets are obtained simultaneously and contain more data than the others [Parrot, 1990]. In Figure 3 it is observed that the two solid lines corresponding to the FBE data (to the left), and to the FBS + FBF data (to the right) in the ZAP3 mode have a similar behaviour where their frequencies overlap, taking into account the standard deviations. On the other hand, the FBS and FBF data in the ZAP3 + ZAP4 mode (dashed lines) do not agree very well with the FBE data. These FBE filters have a similar variation 

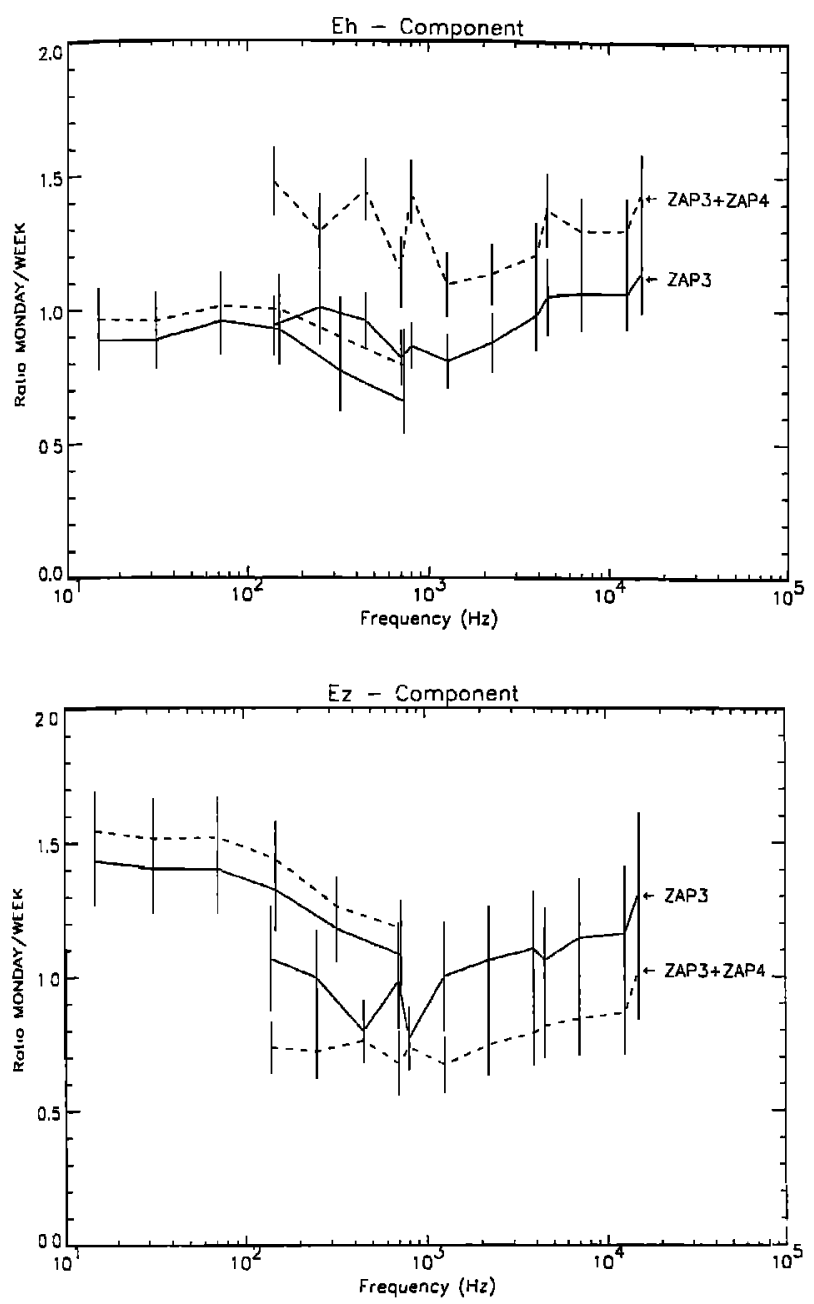

Fig. 3. Amplitude ratio between the average signal recorded on Mondays and the average signal recorded on all the days as a function of the frequency. The upper panel concerns the component $E_{Z}$ and the lower $E_{H}$ (see text for explanation).

in the ZAP3 and in the ZAP3 + ZAP4 modes because $\mathrm{E}_{\mathrm{H}}$ and $E_{Z}$ are always connected. Therefore, the ZAP4 mode introduces some errors in the FBS and FBF data sets. The lower panel of Figure 3 , concerning the $\mathrm{E}_{\mathrm{H}}$ component that is perpendicular to the magnetic field, shows the solid line to be mainly around 1 over the entire frequency range, and thus that there is no effect on Mondays. The $\mathrm{E}_{Z}$ component curves in the upper panel show the ratio to be around 1.5 at frequencies less than $100 \mathrm{~Hz}$, which then decreases with higher frequencies. This shows that the average intensity of the signal recorded by $E_{\mathcal{Z}}$ on Mondays is larger than during the rest of the week, but only at low frequencies, and that there is no similar effect upon $\mathbf{E}_{\mathrm{H}}$.

No study of a possible variation of this phenomenon between industrialized and non-industrialized longitudes was made because, in respect to the validity of the statistic, the data set cannot be separated in many small parts to be just above industrialized zones. It must be noted that no important effect is expected, because this study is not related to the direct observation of PLHR. The power line configuration is more important as it is explained in the next chapter.

\section{Discussion}

PLHR studies usually compare enhancement or reduction of waves or magnetic activity during the days of the week, because generally Saturdays and Sundays are days of minimum electricity consumption. Monitoring the variations at ground level of 2 to $4 \mathrm{kHz}$ wave amplitudes, Park and Miller [1979] observed a minimum on Sundays because they recorded the direct PLHR emitted from a conjugate region and their associated triggered emissions. Such waves propagate in a ducted mode, and their intensities vary with the power consumption. On the other hand, the analysis of the geomagnetic indices performed by Fraser-Smith [1979] indicated a weak maximum during the weekend. He explained that, during weekdays, the PLHR could contribute to the precipitation of energetic particles into the atmosphere, whereas during weekends, when the PLHR are weak, there is less precipitation and the natural wave-particle interaction could amplify the waves. But, when considering the geomagnetic indices, it is understandable that the scale of the magnetic variations will be larger than that of the ELF turbulence, and inaccuracies in the daily variations observed from different sites on the ground should be important. As will be explained hereafter, a survey of the field-aligned current intensities, if it were realistic, would certainly be preferable. The effect presented in this paper is limited upwards to frequencies of about $100-650 \mathrm{~Hz}$, which nearly corresponds to the ion cyclotron frequencies $f_{c i}$. For a frequency range $f>f_{c i}$, and at the altitudes spanned by AUREOL-3, many natural emissions are observed and most of them are electromagnetic. It means that they spread out in space, at least more so than the electrostatic turbulence for $f$ $<f_{c i}$ (for $f<f_{c i}$ the waves are generally electrostatic except in the light-ion trough where the electromagnetic waves may have a frequency as low as $150 \mathrm{~Hz}$ ). This leads to more uncertainties for determination of their original local times and to a smoothing of their daily variations. It may also explain why no effect is observed at VLF frequencies with the FBS and FBF filters. Concerning the variation of $E_{H}$ at low frequencies, its intensity is lower on average than that of $\mathrm{E}_{\mathrm{Z}}$, as was mentioned by Berthelier et al. [1988] and Mounir [1989]. This can be observed in Figure 4 which shows the intensities of $E_{Z}$ and $E_{H}$ for the FBE filters. It also shows that the variation of $E_{H}$ intensities has a power law different from $E_{Z}$, related to the electrostatic turbulence at lower frequencies.

The proposed interpretation to explain the daily variation observed for $E_{Z}$ is the following: - the PLHR penetrate into the ionosphere and are attenuated; - this attenuation leads to modification of the ionospheric currents; - the ionospheric currents induce changes of the field-aligned currents into the magnetosphere; - this modification of the field-aligned currents generates plasma turbulence which can be transformed into kinetic Alfven waves propagating parallel to the Earth's magnetic field [Lysak and Dum, 1983].

The fact that a small decrease in the power consumption (e.g. in France the difference between weekdays and weekend is less than 20\%) induces a large variation in the wave intensity $(93 \%)$ can be explained by a change of the power line configurations during the weekend periods. On Saturday and Sunday, the electric current distribution is equal over the grid and have, seen from the production center, an octopus shape with unclosed lines, because the current is distributed 


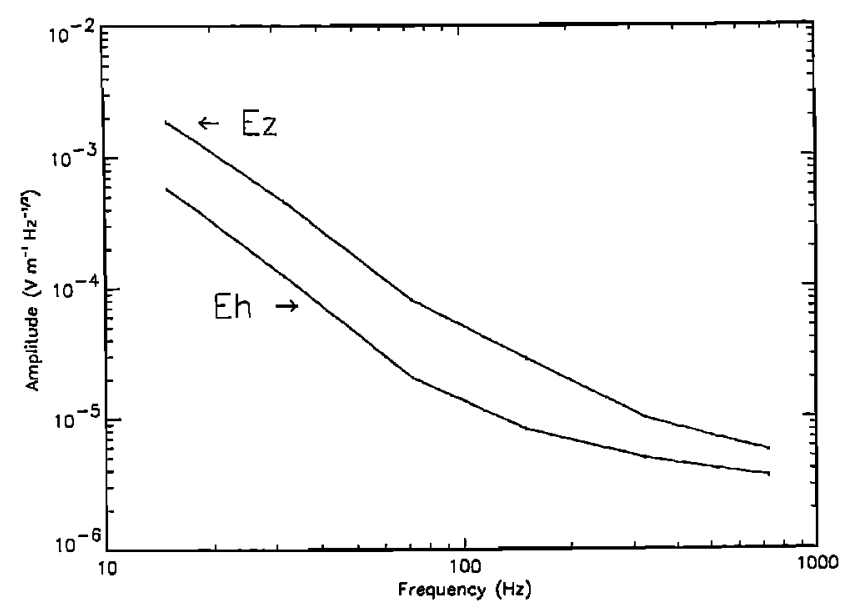

Fig. 4. Average amplitude of the $\mathrm{E}_{\mathrm{Z}}$ and $\mathrm{E}_{\mathrm{H}}$ components as a function of the frequency for the FBE filters. The error bars are indicated.

everywhere to private persons. Whereas during the working days it is mainly distributed to industry, leading to a kind of ring current around the production center with closed lines joining the main consumers. As the penetration coefficient into the ionosphere for a ring-current-like source is higher than for an octopus-shaped radial source, the influence on the ionospheric current is more effective during working days. A full development of this theory, with numerical calculations to estimate the variation of the parallel current in the magnetosphere, is given by Molchanov et al.[1991].

Returning to the two general interpretations considered in the introduction to explain this low-frequency noise, the theory mentioned above supports the Alfven-wave model; the wave is mainly of electrostatic nature with a parallel electric field modulated by the field-aligned currents.

Acknowledgments. The AUREOL-3 program was undertaken jointly by the Centre National d'Etudes Spatiales (CNES) in France, the Space Research Institute (IKI) and INTERCOSMOS in USSR. We thank J.J. Berthelier, who is the principal investigator of the VLF experiment, for the use of the data.

\section{References}

Bell, T. F., J. P. Luette and U. S. Inan, ISEE 1 observations of VLF line radiation in the Earth's magnetosphere, $J$. Geophys. Res., 87, 3530-3536, 1982.

Berthelier, J.J., F. Lefeuvre, M.M. Mogilevsky, O.A. Molchanov, Yu I. Galperin, J.F. Karczewski, R. Ney, G. Gogly, C. Guerin, M. Leveque, J.M. Moreau and F.X. Sene, Measurements of the VLF electric and magnetic components of waves and DC electric field on board the AUREOL-3 spacecraft: the TBF-ONCH experiment, Ann. Geophys., 38, 643-667, 1982.

Berthelier J.J., C. Machard, J.C. Cerisier, A. Berthelier and J.M. Bosqued, ULF electromagnetic turbulence in the high-latitude topside ionosphere, J. Geophys. Res., 93, 5701-5712, 1988.

Bullough K., A.R.L. Tatnall and M. Denby, Man-made ELF/VLF emission and the radiation belts, Nature, 260, 401-403, 1976.

Fraser-Smith, A.C., A week-end increase in geomagnetic activity, J. Geophys. Res., 84, 2089-2096, 1979.
Gurnett D.A., R.L. Huff, J.D. Menietti, J.L. Burch, J.D. Winningham and S.D. Shawhan, Correlated lowfrequency electric and magnetic noise along the auroral field lines, J. Geophys. Res., 89, 8971-8985, 1984.

Helliwell R.A., J.P. Katsufrakis, T.F. Bell and R. Raghuram, VLF line radiation in the Earth's magnetosphere and its association with power system radiation, J. Geophys. Res., 80, 4249-4258, 1975.

Kelley, M.C. and F.S. Mozer, A satellite survey of vector electric fields in the ionosphere at frequencies of 10 to 500 Hertz, 1. Isotropic, high-latitude electrostatic emissions, J. Geophys. Res., 77, 4158-4173, 1972.

Kimura I., H. Higuchi, K. Hashimoto, N. Sato and T. Matsudo, Relationship between power line radiation and VLF wave activities observed in Iceland, Mem. Natl. Inst. Polar Res., Spec. Issue, 47, 97-108, 1987.

Kintner, P.M., Observations of velocity shear driven plasma turbulence, J. Geophys. Res., 81, 5114-5122, 1976.

Kintner, P.M. and C.E. Seyler, The status of observations and theory of high latitude ionospheric and magnetospheric plasma turbulence, Space Sci. Rev., 41, 91-129, 1985.

Lindqvist P.-A. and G.T. Marklund, A statistical study of high-altitude electric fields measured on the VIKING satellite, J. Geophys. Res., 95, 5867-5876, 1990.

Lysak R.L. and C.T. Dum, Dynamics of magnetosphereionosphere coupling including turbulent transport, $J$. Geophys. Res., 88, 365-380, 1983.

Matthews J.P. and K. Yearby, Magnetospheric VLF line radiation observed at Halley, Antartica, Planet. Space Sci., 29, 97-106, 1981.

Molchanov, O.A., M. Parrot, M.M. Mogilevsky and F. Lefeuvre, On a theory of PLHR emissions to explain the daily variations of ELF data observed by a low-altitude satellite, submitted to Annales Geophysicae, 1991.

Mounir H., Turbulence électrostatique dans l'ionosphère à haute latitude, Thèse de Doctorat, Univ. of Paris 6, 1989.

Park, C.G. and T.R. Miller, Sunday decreases in magnetospheric VLF wave activity, J. Geophys. Res., 84, 943-950, 1979.

Parrot, M., World map of ELF/VLF emissions as observed by a low-orbiting satellite, Annales Geophysicae, 8, 135-146, 1990.

Temerin M., The polarization, frequency and wavelength of high latitude turbulence, J. Geophys. Res., 83, 2609-2616, 1978.

Tomizawa I. and T. Yoshino, Power line radiation observed by the satellite OHZORA, J. Geomag. Geoelectr., 37, 309-327, 1985.

F. Lefeuvre and M. Parrot, Laboratoire de Physique et Chimie de l'Environnement, 3A, Avenue de la Recherche, 45071 Orléans Cedex 02, France.

O.A. Molchanov, Institute of Physics of the Earth, B. Gruzinskaya 10, Moscow 123810, Ussr.

M.M. Mogilevsky, Space Research Institute, Ussr Academy of Sciences, ul. Profsoyuznaya 88/34, Moscow 117810, Ussr.

(Received: December 10, 1990;

Revised: February 04, 1991;

Accepted: April 15, 1991.) 